\title{
Efeitos da centralização e descentralização no processo brasileiro de municipalização: 0 caso da região norte
}

\author{
Marília STEINBERger \\ Regina De SouZa Maniçoba*
}

\begin{abstract}
The period of decentralisation, starting with the Constitution on 1988, generated an intense territorial fragmentation in the country, in particular, within the Northern Region. A comparative study of the life quality in both the old and new municipalities in this region has shown that in the majority of the new ones, contrary to what was expected, there was an improvement. This fact, besides contributing to demystify the idea of the creation of new municipalities as a negative factor for the population, highlights a different aspect in the traditional debate that relates this creation with the local interests of obtaining more resources from the Central Government, and thus reinforces their financial dependency.
\end{abstract}

Keywords: decentralisation, territorial fragmentation, life quality, city, territory.

\section{Resumo}

O período de descentralização, iniciado com a Constituição de 1988, gerou uma intensa fragmentação territorial no país e, em particular, na Região Norte. A investigação comparativa sobre a qualidade de vida nos municípios novos e antigos nesta região mostrou que, na maioria dos novos, ao contrário do esperado, houve de fato uma melhoria. Tal constatação, além de contribuir para desmistificar a idéia da criação de novos Municípios como um fator negativo para a população, ressalta um aspecto diferente no debate tradicional que relaciona esta criação apenas aos interesses locais de obter mais recursos do Governo Central e, assim, reforçar a dependência financeira.

Palavras clave: descentralização, fragmentação territorial, qualidade de vida, cidade, território.

\footnotetext{
*Universidade de Brasília. Correos-e: rtlia@solar.com.br y manicoba@unb.br.
} 


\section{Introdução}

A Região Norte $^{1}$ (figura I) tem apresentado, em pouco mais de quarenta anos, um considerável aumento em seu processo de urbanização. Conforme dados do Instituto Brasileiro de Geografia e Estatística (IBGE), o crescimento urbano verificado na região foi o maior do país: a população urbana, que correspondia a aproximadamente 1.6 milhões de habitantes em 1970, atingiu mais 3 milhões em 1980, chegou a quase 6 milhões em 1990 e ultrapassou 9 milhões em 2000.

\section{Figura I \\ Regiões geográficas}

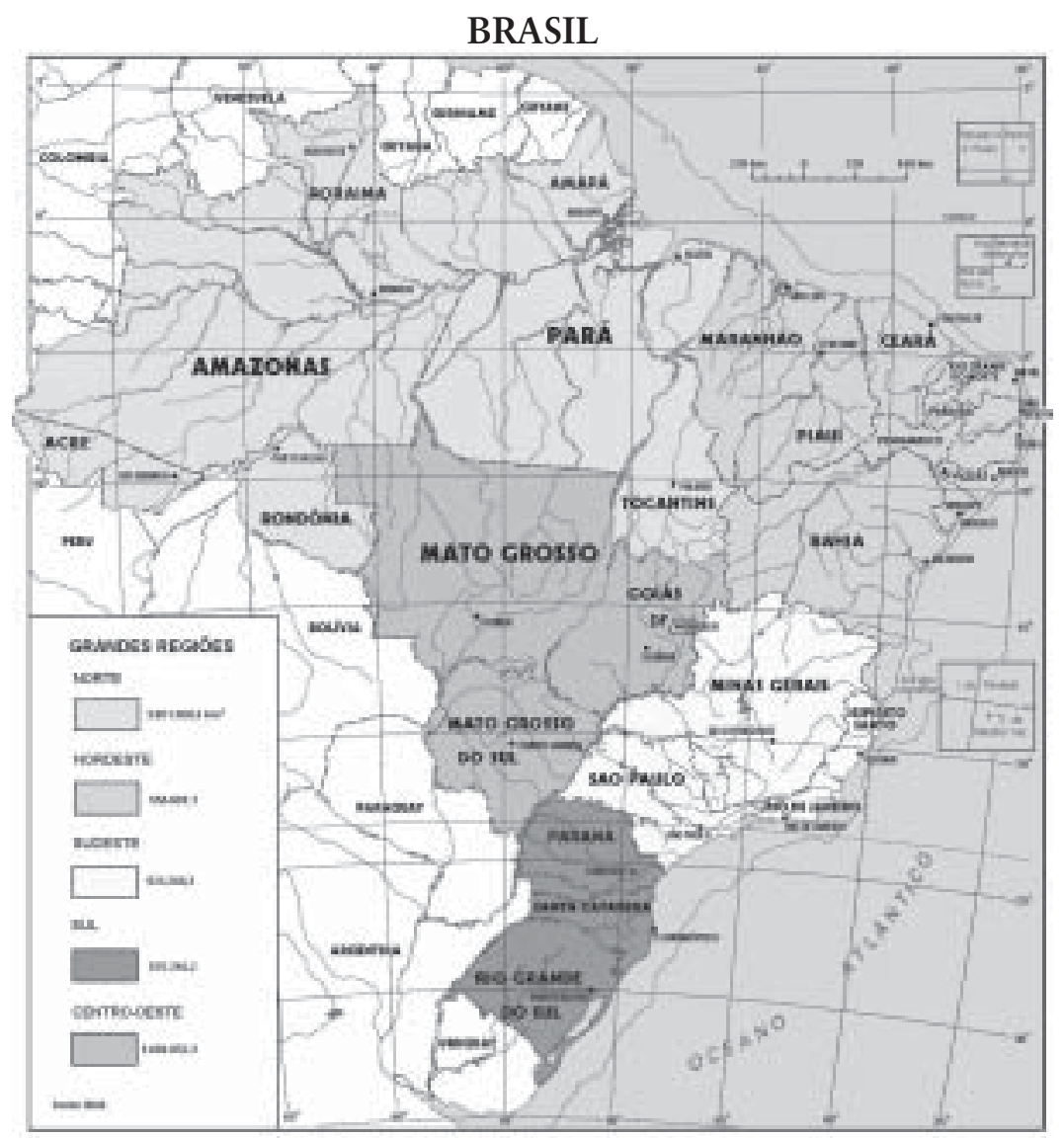

Fonte: Instituto Brasileiro de Geografia e Estatística (IBGE, http://www.ibge.gov.br).

${ }^{1}$ De acordo com a divisão regional adotada pelo IBGE, o Brasil é dividido em cinco regiões: Norte, Sul, Nordeste, Sudeste, Centro-Oeste. 
Alguns autores consideram que a criação de novos Municípios, ${ }^{2}$ permitida a partir da vigência da Constituição da República Federativa do Brasil de 1988, é um dos principais fatores responsáveis por este aumento. Outros argumentam que a descentralização e a autonomia, preconizadas nesta Carta Magna, vem gerando, acima de tudo, uma fragmentação territorial cujos efeitos sobre a população regional ainda são pouco estudados.

Tomando como base estas questões, pretende-se analisar as conseqüências da criação de novos Municípios na Região Norte depois de 1988, no que diz respeito à melhoria ou agravamento da qualidade de vida de sua população. Nesse sentido, a título de ensaio, escolheu-se o número de domicílios ligados à rede de água como indicador para realizar uma análise comparativa entre Municípios criados após 1988 e aqueles dos quais foram desmembrados, por ser este considerado uma referência básica em políticas públicas.

Para abordar tal tema, este artigo está dividido em três seções. A primeira traça um breve histórico sobre o processo de municipalização brasileiro e o duplo movimento de centralização-descentralização, emanado a partir das várias Constituições promulgadas desde 1891. A seguir, discute-se o entendimento de fragmentação territorial e de qualidade de vida, à luz de dois conceitos básicos: território e cidade. Por fim, apresenta-se um quadro geral sobre a criação de Municípios na Região Norte após 1988, e selecionam-se alguns deles para mostrar a qualidade de vida anterior e posterior à fragmentação.

\section{Descentralização e municipalização no Brasil}

Discorrer sobre descentralização não é uma tarefa simples, pois existem controvérsias a respeito do seu significado. Muitos autores, a exemplo de Limana (1999), enfatizam que no Brasil sempre prevaleceu a centralização. Consideram que no Império $^{3}$ ela foi fundamental para a sobrevivência econômica, centrada no binômio escravo-latifúndio, herança do período colonial. Argumentam que, com o advento da República, mudou-se o regime,

${ }^{2} \mathrm{O}$ art. 18 da Constituição define que a organização político-administrativa da República Federativa do Brasil compreende a União, os Estados, o Distrito Federal e os Municípios, todos autônomos, nos termos da mesma.

${ }^{3} \mathrm{O}$ Brasil foi colônia de Portugal até 1822 quando foi proclamada a independência. Teve início então o período Imperial que compreendeu: o Primeiro Reinado (18221831), a Regência (1831-1840) e o Segundo Reinado (1840-1889). 
mas não a centralização. Entretanto, outros autores, como Steinberger (1994), mostram que a história do Brasil sempre foi marcada por movimentos alternados de centralização e descentralização, tanto no período colonial, quanto no Império e na República.

Mas em que consiste exatamente o termo descentralização? Para Souza (1998):

[...] apesar de políticas descentralizadas estarem em voga, o conceito de descentralização é vago e ambíguo. A popularidade da descentralização respalda-se em vários fatores, dentre eles nos ataques da direita e da esquerda contra o poder excessivo dos governos centrais [...]. Enquanto alguns autores enfatizam a desconcentração administrativa, outros vêem a descentralização como uma questão política que envolve uma efetiva transferência de autoridade para setores, parcelas da população ou espaços territoriais antes excluídos do processo decisório.

De fato, em geral, o debate sobre descentralização comporta duas acepções: o papel do estado em relação à iniciativa privada, aos movimentos sociais e às organizações não governamentais, onde a descentralização está ligada à redução do papel do Estado que, de provedor e executor, passa a ser eminentemente regulador; e o papel da União em relação aos estados e Municípios, que envolve a partilha de poder entre as três instâncias da administração do país. Neste trabalho, o termo descentralização está sendo utilizado com a segunda acepção, na medida em que ela permite discutir o papel do município como entidade da federação e órgão gestor dos governos locais.

Para entender a importância do Município, cabe apresentar uma breve descrição da sua história, desde o período colonial, passando pelas Constituições republicanas, até a atualidade. Isso porque, assim como a própria história do país, a história do Município também sempre foi marcada por movimentos de centralização e descentralização.

O resgate desta história, realizado pelo Instituto Brasileiro de Administração Municipal (IBAM) (IBAM, 2004), mostra que todas as vilas brasileiras, desde as primeiras, fundadas pelos portugueses, seguiram o modelo e a estrutura das administrações municipais lusitanas que possuíam "um Presidente, três Vereadores, um Procurador, dois Almotacés, um Escrivão, um Juiz de Fora vitalício e dois Juízes Comuns, eleitos com os Vereadores". Tal estrutura revela que, de uma certa maneira, as vilas coloniais comportavam os três poderes municipais que hoje se denominam de 
Executivo, Legislativo e Judiciário. No entanto, apesar da submissão dos Municípios à Metrópole, estes tiveram mais autonomia do que se supunha, pois em períodos de descentralização, conseguiram até algumas reconhecidas "vitórias, desafiando a Coroa, como é o caso da criação de novas vilas [...], que ocorreu sem autorização real, pela força e determinação do povo, como exemplificaram os fatos registrados em Campos, Parati e Pindamonhangaba, no século XvıI". Já, no período imperial predominou o "cerceamento da atuação das Câmaras Municipais, que perderam funções políticas e financeiras", tendo sido transformadas em "corporações meramente administrativas", embora tenham ocorrido movimentos de descentralização, principalmente entre 1830 e 1840 . Esta alternância entre conquista e redução de autonomia municipal, que marcou os períodos colonial e imperial, foi se repetindo ao longo da história.

Ainda segundo o IBAM, na República Velha, ${ }^{4}$ foi a centralização que garantiu a permanência das oligarquias regionais, e seus respectivos desdobramentos estaduais, no poder nacional. Assim, apesar da Constituição de 1891 trazer, entre suas premissas, a autonomia dos Municípios, estes se tornaram objeto de manipulação ostensiva destas oligarquias. Os acontecimentos políticos ocorridos neste período acabaram por precipitar a reforma constitucional de 1926 que deu à União o direito de intervir nos Estados para proteger a autonomia municipal pondo fim assim, ao abuso e arbitrariedade dos Estados sob seus Municípios. Com o fim da República Velha em 1930 e o início da Era Vargas, a Constituição de 1891 foi suspensa tendo sido promulgada uma nova Constituição em 1934. Com esta:

[...] restabelecia-se a Federação, reduzia-se a competência dos Estados, inclusive sobre a organização municipal, cuja autonomia adquire nível de importância equivalente à da União e à dos Estados, explícita e claramente definida no artigo 13.

Porém, novamente os acontecimentos políticos acabaram por impedir que a autonomia dos municípios pudesse ser exercida. Com o golpe de Estado, em 1937, teve início o Estado Novo, um período de intensa centralização política, quando as Câmaras

\footnotetext{
${ }^{4}$ Tradicionalmente, o período republicano no Brasil é dividido em: República Velha, também chamada de República das Oligarquias (1889-1930); Era Vargas que se iniciou com a Revolução de 1930 e se estendeu até 1945, compreendendo o denominado Estado Novo (1937-1945); República Populista (1945-1964); Ditadura Militar (1964-1985); e Nova República (1985 em diante).
} 
Legislativas foram dissolvidas e os estados passaram a ser governados por Interventores Federais, a quem cabia a escolha dos Prefeitos. Seguindo o mesmo espírito de centralização, uma nova Constituição foi promulgada em 1937. Entre as conseqüências desta, Ferreira (1986) ressalta a diminuição da autonomia dos estados e dos Municípios. Entretanto, o IBAM (2004) chama atenção para dois pontos que garantiram a sobrevivência dos $\mathrm{Mu}-$ nicípios:

(a) manteve-se a arrecadação municipal sobre indústrias e profissões [...]; (b) generalizou-se nos Estados a criação de Departamentos de Assuntos Municipais, o que, em princípio, visava controlar os governos locais, mas, por outro lado, tinha funções de assistência técnica que muito contribuiu para a racionalização das administrações municipais [...]

Com a deposição de Getúlio Vargas, em 1945, o governo do general Eurico Gaspar Dutra ${ }^{5}$ promulgou uma nova Constituição em 1946. Nesta, os princípios democráticos foram retomados e, ao mesmo tempo, houve um restabelecimento parcial da autonomia dos Estados e Municípios (Ferreira, 1986). Parcial porque a feição municipal que emergiu do texto constitucional dispunha que o Município era uma das três esferas político-administrativas do país, junto com a União e os estados, e que seus Prefeitos e Vereadores seriam eleitos pelo povo, à exceção dos que abrigassem capitais, estâncias hidrominerais, bases ou portos militares, e fossem fundamentais para a defesa externa. Impediu-se assim, que quase a metade da população brasileira tivesse o direito de escolher seus Prefeitos e Vereadores.

A Constituição posterior, de 1967, foi fortemente influenciada pela atmosfera de autoritarismo e restrição de direitos que marcaram a ascensão dos militares ao poder em 1964. A autonomia presente na Constituição anterior, assim como a própria criação de novos municípios, ficaram comprometidas, devido às novas exigências então impostas. Delegou-se às Assembléias Legislativas dos Estados, a criação, incorporação, fusão e o desmembramento de Municípios, que devia ocorrer de acordo com os seguintes critérios: população superior a 10 mil habitantes ou não inferior a cinco milésimos do total de habitantes do estado; eleitorado não inferior a $10 \%$ da população; centro urbano com,

${ }_{5}^{5}$ Durante a República Populista os seguintes presidentes se sucederam no poder: Eurico Gaspar Dutra (1946-1951), Getúlio Vargas - nova Era Vargas (1951-1954), Café Filho (1954-1956), Juscelino Kubitschek (1956-1961), Jânio Quadros (1961), João Goulart (1961-1964). 
no mínimo, 200 casas; e arrecadação municipal no último exercício de, no mínimo, $0.005 \%$ da receita estadual. Além disso, deveria ser realizado um plebiscito entre os munícipes (Freitas, 1998). Entretanto, dois anos depois, a Emenda Constitucional de 1969, segundo Rodrigues (2003) congelou a divisão territorial brasileira e, com ela, a criação de novos municípios.

A década de 80 inaugurou uma nova era no país. A continuidade do processo de abertura política, iniciado em fins dos anos 70 , teve como marco as eleições diretas para governadores, prefeitos, senadores, deputados federais e estaduais realizadas em novembro de 1982, em decorrência da aprovação de uma Emenda Constitucional naquele mesmo ano. Entretanto, somente em 1985, também por Emenda Constitucional, restabeleceram-se as eleições diretas para todos os Municípios, inclusive os considerados de segurança nacional pelo regime militar. No ano seguinte o Congresso ganhou poderes constituintes para elaborar uma nova Constituição que foi promulgada em fins de 1988.

Com ela iniciou-se um novo período de descentralização na história dos Municípios brasileiros. Isso porque, seguindo a premissa de autonomia, o artigo 18, associado ao artigo 30, facultaram o descongelamento da divisão territorial brasileira. Os Estados ganharam a possibilidade de incorporar-se entre si, subdividir-se ou desmembrar-se para se anexarem a outros, ou formarem novos Estados. Paralelamente, também cabe aos Estados a criação, incorporação, fusão e o desmembramento de Municípios, mediante consulta prévia das populações dos Municípios envolvidos, por meio de plebiscito. Por sua vez, entre as competências dos Municípios está a prerrogativa de criar, organizar e suprimir distritos.

Além disso, a Constituição de 1988 trouxe ainda, entre os dispositivos referentes aos Municípios, outro ponto importante: o aumento nos percentuais destinados pela União ao Fundo de Participação dos Municípios (FPM). ${ }^{6}$ O percentual de $17 \%$ instituído pela Emenda Constitucional de 1983 foi elevado para 20.5\%.

Impulsionados pela autonomia e pelo aumento do FPM, os Estados permitiram que o número de Municípios aumentasse significativamente. Conforme os dados do IBGE, em 1980 existiam 3,991 Municípios e, em 2000, esse número saltou para 5,507 o que, em princípio, denota fragmentação territorial. Considerando as cinco regiões brasileiras, definidas pelo IBGE, é possível ob-

${ }^{6}$ O FPM é uma transferência constitucional feita pela União aos Municípios e foi instituído pela Lei ${ }^{\circ} 5.172$ de 25/10/1966. 
servar que em termos absolutos, a Região Sul e a Região Nordeste, foram as que mais criaram novos Municípios entre 1980 e 2000 - respectivamente 440 e 412, seguidas pela Sudeste com 256, Norte com 246 e, finalmente a Centro-Oeste com 162. Entretanto, quando se verifica a relação entre o número de Municípios novos e os já existentes, a Região Norte desponta como aquela em que os novos representam mais do que o dobro, $121 \%$, ao passo que nas demais eles correspondem, no máximo, a 60\%, caso da Região Sul. Por esta razão, a Região Norte será utilizada como estudo de caso neste artigo.

Com o objetivo de conter a desenfreada criação de novos Municípios, em fins de 1996, foi proposta e aprovada uma Emenda Constitucional em que se manteve a competência estadual para criar, incorporar, fundir e desmembrar Municípios, mas acrescentou-se a necessidade de elaborar e divulgar "Estudos de Viabilidade Municipal", a serem apresentados e publicados na forma da lei. Para constatar a eficácia desta Emenda, examinaram-se os dados referentes ao ano de instalação dos novos $\mathrm{Mu}-$ nicípios nos sete Estados da Região Norte. Para o conjunto regional, segundo informações especiais enviadas pelo IBGE, 44 Municípios passaram a ter existência jurídica no ano de 1997 e apenas um em 1998. Admitindo que este número esteja relacionado à Municípios criados entre 93 e 96, cujos processos de instalação já se encontravam em andamento por ocasião da aprovação da Emenda, pode-se dizer que na Região Norte, de fato, houve um freio na fragmentação. Entretanto, quando se consulta o site do IBGE referente à "Organização do Território", o arquivo dos Municípios instalados em 2001 mostra o surgimento de 54 novos Municípios no Brasil como um todo (30 na Região Sul, todos no Rio Grande do Sul; 17 na Região Centro-Oeste; 5 na Nordeste; e 2 na Sudeste). Mas, afinal o que levou o legislador a preocupar-se em conter a fragmentação territorial? Ela é danosa ou benéfica? Para quem?

Becker (2003: 655), ao enumerar as características e os indicadores que vem contribuindo para a Amazônia tornar-se uma "floresta urbanizada", afirma que:

Entre 1970 e 1980, foram principalmente a imigração e a mobilidade do trabalho os fatores fundamentais do crescimento urbano. Após 1988, a criação de municípios torna-se uma razão central no crescimento urbano, além da mobilidade intra-regional, e muito menos a migração externa, que se reduziu. 
$\mathrm{Na}$ verdade essa preocupação não é nova. Alguns anos antes a mesma autora (Becker, 2000: 57), ao construir cenários de curto prazo para o desenvolvimento da Amazônia assinalava:

[...] o ritmo de urbanização, embora acelerado até agora, tende a se desacelerar por duas razões. Primeiro, a multiplicação de núcleos na década de 90 se fez em grande parte devido a um intenso processo de formação de novos municípios - em que cada um tinha como sede uma cidade (qualquer que fosse o seu tamanho) - mas que parece não ter ido adiante. Segundo ocorreu redução da imigração [...] A desconcentração urbana mais recente não foi fruto da migração, mas sim da criação de municípios em decorrência da Constituição de 1988, que estabelece a transferência de recursos e, em menor proporção, de responsabilidades para o município, em nome da descentralização. A questão crucial é saber se tal descentralização corresponde, efetivamente ou não, a uma maior autonomia, ou seja, uma verdadeira emancipação política e financeira.

$\mathrm{Na}$ mesma linha de argumentação, Steinberger e Ferreira (2003: 5), referem-se explicitamente à fragmentação territorial e à governabilidade decorrente da criação de novos Municípios. Assim:

A Constituição de 88 retomou a possibilidade de criação de novos municípios, o que não só trouxe a fragmentação territorial, como fomentou o crescimento urbano com a passagem de vilas e povoados à categoria de cidade. Atualmente, existem mais de 5.700 municípios e, portanto, igual número de cidades, além de aproximadamente $15 \mathrm{mil}$ núcleos urbanos, o que nos remete à questão da governabilidade do espaço urbano. A descentralização, como princípio básico da Constituição, deu maior autonomia aos municípios, sem que, no entanto, todos eles tivessem uma correspondente base econômica, financeira, gerencial e logística para fazer frente às novas atribuições.

O reconhecimento de que a criação dos Municípios gera fragmentação territorial e exerce uma influência significativa sobre o crescimento urbano, aliado ao questionamento da descentralização corresponder ou não à autonomia e governabilidade, constituem aspectos, indiscutivelmente, cruciais para o debate. Entretanto, ainda não chegam ao fundo da questão, ou seja, as conseqüências da criação de novos Municípios no que diz respeito à melhoria ou agravamento das condições de vida de sua população. Assim, não permitem responder se a fragmentação territorial, decorrente da criação de novos Municípios, é danosa ou benéfica, e para quem. A importância do presente artigo está exatamente em avançar sobre este ponto, analisando a qualidade 
de vida da população de alguns Municípios criados após 1988 e daqueles dos quais foram desmembrados. Acredita-se que estudos e investigações desse tipo podem subsidiar a formulação de políticas públicas.

Antes de entrar na discussão sobre o caso específico da Região Norte, cabe apresentar uma breve discussão sobre fragmentação territorial e qualidade de vida, à luz dos conceitos de território e cidade que se constituem a base da temática ora apresentada.

\section{Fragmentação territorial e qualidade de vida: uma discussão conceitual}

Em geral, as expressões fragmentação territorial e qualidade de vida não têm merecido abordagens conjuntas porque, à primeira vista, elas não estão visivelmente relacionadas. Para buscar a sua relação é preciso considerar que a fragmentação territorial faz parte de um processo mais amplo, o de produção e organização espacial, e que, por outro lado, a qualidade de vida está inserida em um processo também mais amplo, o de integração social. A partir daí é possível perceber que esses dois processos, o de produção e organização espacial e o de integração social, aliados a outros dois, os processos de crescimento econômico e de formação política, constituem-se os vetores de um todo bem mais complexo que é o desenvolvimento. Com base neste entendimento, a relação entre fragmentação territorial e qualidade de vida ganha visibilidade. Esta acepção, embora proposta por Steinberger e Ferreira (2003), no âmbito das premissas de uma Política Urbana Nacional 2003-2006, pode ser transposta para o tema ora tratado, principalmente no que diz respeito ao vetor espacial.

Ao discorrer sobre o processo de produção e organização espacial, Corrêa (1995: 35-6) explica:

No longo e infindável processo de organização do espaço o Homem estabeleceu um conjunto de práticas através das quais são criadas, mantidas, desfeitas e refeitas as formas e as interações espaciais. São as práticas espaciais, isto é, um conjunto de ações espacialmente localizadas que impactam diretamente sobre o espaço, alterando-o no todo ou em parte ou preservando-o em suas formas e interações espaciais. [...] As práticas espaciais são ações que contribuem para garantir os diversos projetos. São meios efetivos através dos quais objetiva-se a gestão do território, isto é, a administração e o controle da organização espacial em sua existência e reprodução. [...] as práticas espaciais são as seguin- 
tes: seletividade espacial, fragmentação - remembramento espacial, antecipação espacial, marginalização espacial [...] (grifo nosso).

Para Corrêa (1995: 37), fragmentação é uma prática espacial corrente, uma vez que o espaço está sempre sendo dividido em unidades territoriais cujas porções são controladas por diversos agentes, sejam eles "uma comunidade aldeã, uma Cidade-Estado, uma organização religiosa, o Estado moderno, poderosas empresas ou grupos que se identificam por uma dada especificidade e numa dada porção do espaço". Entre os vários exemplos que cita, o autor refere-se explicitamente à fragmentação de Municípios no território brasileiro.

As colocações acima também mostram que a fragmentação espacial está associada à gestão do território. Território entendido como "espaço revestido da dimensão política, afetiva ou ambas" (Corrêa, 1994: 251). Entendido também como "espaço onde se projetou um trabalho, seja energia e informação, e que, por conseqüência, revela relações marcadas pelo poder" (Raffestin, 1993: 144). Ou ainda como "espaço definido por e a partir de relações de poder" (Souza, 1995: 78).

No que diz respeito à criação de novos Municípios, essa imbricação entre fragmentação, território e poder, leva a indagar de onde emana o poder para sugerir que o território municipal seja fragmentado. Em princípio, como já ressaltado antes, este poder foi outorgado pela própria Constituição que, ao abrir a possibilidade de se criarem novos Municípios e, paralelamente, aumentar o percentual do FPM, de uma certa maneira, contribuiu para viabilizar a fragmentação. No entanto, falta identificar qual a motivação para o uso extensivo dessa prerrogativa.

Reconheceu-se anteriormente que a criação de Municípios gerou uma multiplicação de cidades e um aumento do ritmo de urbanização. Estará a motivação ligada à "condição urbana”? Para responder é preciso lembrar que para a maior parte dos países, o critério adotado para se definir cidades é o demográfico. Entretanto, segundo Veiga (2002: 65), apenas no Brasil, El Salvador, Equador, Guatemala e República Dominicana, todas as sedes de Município são cidades. Ele ressalta que, no Brasil, isso se deve à vigência plena do Decreto-lei 311/1938 e à desconsideração de outras variáveis como tamanho da população, densidade e localização. Assim, muitas localidades com uma população ínfima são cidades apenas por serem sede municipal. Esse decreto somado ao dispositivo constitucional do artigo 18 , antes referido, 
não só reforça como confirma que criar novos Municípios equivale a criar novas cidades, o que sugere a necessidade de discutir brevemente os conceitos de cidade e de espaço urbano no que se refere à sua relação com o(s) poder(es).

Cidade, conforme o senso comum, é o lugar de concentração da população e de atividades. Vários estudiosos têm se dedicado a buscar definições de cidade. Rolnik (1988) mostra que a compreensão da cidade envolve diferentes perspectivas, entre as quais ela destaca: a cidade como um imã, a cidade como escrita, a cidade política e a cidade como mercado. Imã porque é um campo magnético que atrai, reúne e concentra os homens. Escrita porque, como local de moradia, trabalho e produção, gera excedentes e proporciona acumulação de riquezas e conhecimentos registrados pela escrita. A cidade política diz respeito ao exercício de dominação da autoridade político-administrativa sobre o conjunto dos moradores. Por fim, a cidade como mercado surge devido à aglomeração de uma numerosa população em um espaço limitado, que estabelece não só a divisão do trabalho entre campo e cidade, como uma especialização do trabalho no seu interior. Aliás, na concepção weberiana a "cidade" é um lugar de mercado (Weber, 1987). Já Borja (1997: 85), ressalta a importância de se entender a cidade não apenas como:

\section{[...] um território que concentra um importante grupo humano e uma grande diversidade de atividades, mas também como um espaço sim- biótico (poder político/sociedade civil) e simbólico (que integra cultu- ralmente e confere identidade coletiva a seus habitantes, tendo valor de troca com o exterior) que se transforma em um campo de respostas possíveis aos desafios econômicos, políticos e culturais de nossa época.}

Preteceille (1996), por sua vez, define a cidade como o lugar da intervenção da política - lugar do exercício e da concentração do poder político. Souza (1997) considera a cidade como o lugar das redes, o lugar da técnica e destaca a associação conceitual entre cidade e urbano, utilizando Santos (in Souza, 1997) para quem: "a cidade é o concreto, o conjunto de redes, enfim a materialidade visível do urbano enquanto que este é o abstrato, porém o que dá sentido e natureza à cidade”. Essa associação entre cidade e urbano tem como base o conceito de espaço. Espaço que, como diz Lefebvre (1999: 49), sempre foi político porque "a existência urbana se confunde com a existência política”. 
Steinberger e Romero (2000: 16) definem o espaço urbano como "espaço de aglutinação de interesses socioeconômico e político-cultural”, ou seja:

[...] espaço relacional, cujo alcance e significado é definido por relações externas e internas. As externas estão ligadas não somente à concentração da oferta e demanda de emprego, bens e serviços, como enfatizado nas teorias neoclássicas de economia urbana e regional, mas, fundamentalmente, ao fato do espaço urbano ser ponto de apoio para a formação de uma rede urbana por onde circulam os interesses. Ao mesmo tempo, internamente, o espaço urbano configura-se como um sítio de condições privilegiadas, onde a construção física, a localização e o próprio modo de vida, propiciam a implantação de assentamentos humanos que aglomeram pessoas, atividades, idéias e informações.

Além disso, o espaço urbano é, por excelência, o lócus de negociação de agentes e atores sociais, que possuem interesses territoriais distintos e expressam seu poder sob a forma de conflitos e tomadas de decisões. Em outras palavras, os espaços urbanos são políticos e caracterizam-se como territórios de encontros, onde ocorrem articulações inclusive sobre os negócios do mundo rural (Steinberger, 2001a).

Tais articulações e negociações se materializam nas cidades, entendidas elas mesmas como manifestações do poder de agentes e atores sociais. Assim, sugere-se aqui que a motivação para criar novos Municípios e, conseqüentemente, no caso do Brasil, novas cidades, é de caráter eminentemente político. É a fragmentação das áreas de poder e mando existentes e a possibilidade de criar novas que está por trás do surgimento de tantos Municípios.

Essa sugestão é apoiada pela idéia de Becker (1990) de que o novo significado da urbanização na Amazônia se relaciona ao papel dos núcleos urbanos como lócus da ação política-ideológica do estado, na medida em que abrigam: a sede do aparelho de estado local, da Igreja e dos grupos hegemônicos da fração nãomonopolista em formação na nova sociedade local; e o lugar de preparação da população para exercer seu papel na sociedade.

A mesma autora, em um trabalho mais recente (Becker, 2003: 655-6), reafirma tal idéia ao dizer:

[...] há que se registrar a importância da dimensão política no processo de urbanização regional. A começar pela presença do aparato institucional dos diferentes escalóes do governo, seguindo pelo papel das lideranças locais e seus lobbies na própria criação de vilas e distritos, e pela presença das organizações das sociedades civis que se localizam em 
cidades que servem a redes sociais, nem sempre correspondendo às capitais regionais. Em suma, o processo de urbanização regional não está associado a dinâmicas econômicas, nem à industrialização nem à agricultura moderna, a não ser em áreas localizadas. Mas se a base econômica municipal e urbana é fraca, seu papel político é essencial nas tomadas de decisões para controle do território e para a gestão ambiental, constituindo parceria política não mais negligenciável.

Embora, admita-se que este tipo de discussão precisa ser mais aprofundado, considera-se que, para fins deste artigo ela representa um avanço em termos do entendimento sobre o significado da criação de novos Municípios.

Com relação ao segundo processo antes referido, o de integração social, cabe aqui discutir brevemente o entendimento sobre a expressão qualidade de vida, de modo a construir uma base analítica para investigar as conseqüências da criação de novos Municípios no que diz respeito à melhoria ou agravamento das condições de vida de sua população.

Um aspecto importante a ser inicialmente observado é que expressão qualidade de vida, similarmente à fragmentação territorial, que está ancorada nas teorias do espaço e nos conceitos de território, cidade, urbano e poder, também possui uma base teórico-conceitual, ancorada no "welfare state" (Estado do bemestar social) e no conceito de eqüidade. A despeito disso, a preocupação dos estudiosos do assunto, na maioria das vezes, está centrada na busca de parâmetros, indicadores e modelos para mensurar a qualidade de vida Brito (in Steinberger 2001b: 23) relata que:

A idéia de qualidade em contraposição à de quantidade [...] nasceu no mundo da empresa privada, nos anos 50. Concebida, inicialmente, como aptidão dos produtos em relação aos usos, passou a significar satisfação de necessidades e hoje é entendida como atendimento a certas especificações. Por outro lado, o mundo dos serviços públicos [...] apresenta uma dimensão ideológica que constitui o denominado 'mito legitimante', base do Estado do Bem-Estar Social, em que o acesso e o padrão de qualidade dos serviços deve ser igual para todos. Nesse mundo, ao contrário do anterior, não há clientes que realizam uma demanda ativa, mas usuários que realizam uma demanda passiva.

O "welfare state" foi a alternativa histórica, das sociedades capitalistas do pós-guerra, para tratar das desigualdades sociais. A partir daí buscou-se uma ação combinada entre política econômica e Estado do bem-estar social. Enquanto a primeira proporcionava crescimento a segunda amenizava tensões e conflitos 
gerados por este, objetivando alcançar uma distribuição mais eqüitativa dos seus frutos e, conseqüentemente, melhorar a qualidade de vida.

Souza (in Fernandes, 1997: 6) considera que a definição de qualidade de vida abrange tanto "a distribuição dos bens de cidadania - os bens e direitos que uma sociedade, em dado momento, julga serem essenciais - quanto à de uma série de bens coletivos de natureza menos tangível e nem por isso menos reais em suas repercussões sobre o bem-estar social". Dessa forma, para a autora, qualidade de vida pode ser vista como a totalidade das condições nas quais as pessoas vivem.

Nicácio (1982) ressalta que o avanço tecnológico e o aumento do nível de renda contribuíram para o crescente número de estudos sobre qualidade de vida. Argumenta que, ao se considerar a qualidade de vida de uma forma ampla, o uso dos indicadores meramente econômicos, como o Produto Nacional Bruto (PNB) e a renda per capita, passa a ser questionado tendo em vista que o crescimento econômico implica num custo ambiental e social. Assim, o autor enfatiza que os estudos mais recentes têm se dedicado a apontar indicadores que envolvem fatores ambientais, políticos, econômicos e sociais. Nesse sentido, ele identifica indicadores mais diretamente relacionados às necessidades básicas do indivíduo no que diz respeito a sua sobrevivência: saúde, habitação, segurança, transporte e educação. Villarinho (2000: 59) sugere que a qualidade de vida seja definida por três aspectos:

O primeiro diz respeito ao nível de acesso aos bens de serviços (saúde, transporte, saneamento, educação, moradia, alimentação, lazer, cultura, etc.). O segundo, à urbanidade (relação de vizinhança) e o último, à qualidade ambiental do local (área de moradia - adequada ou não, existência de local apropriado para colocar o lixo, etc.).

Estes tipos de indicadores, mais voltados para o social, tem sido muito utilizados por organismos nacionais, como o Instituto de Pesquisa Econômica Aplicada (IPEA), e internacionais, como o Banco Mundial e a Organização das Nações Unidas (ONU), principalmente no âmbito do Programa das Nações Unidas para o Desenvolvimento (PNUD), onde se adota o Índice de Desenvolvimento Humano (IDH) construído a partir da combinação de esperança de vida, nível de educação e rendimento e em diferentes âmbitos geográficos: internacional, nacional, regional e local.

Além disso, cumpre destacar que a definição de qualidade de vida varia também de acordo com o enfoque da área de conheci- 
mento em que está sendo aplicada. Por exemplo, nos estudos na área de saúde, a ênfase é para a qualidade de vida física do indivíduo. Já na Administração e na Economia, o enfoque volta-se para a promoção de saúde no local de trabalho visando o aumento de produtividade. $\mathrm{Na}$ área do Planejamento Urbano, por sua vez, são considerados indicadores de infra-estrutura.

No que diz respeito à criação de novos Municípios, acreditase que esta discussão sobre qualidade de vida contribui para identificar os tipos de indicadores mais relevantes para se empreender a análise do caso da Região Norte. Entretanto, não basta dizer que se devem adotar indicadores sociais, econômicos, ambientais e políticos em uma análise das conseqüências da fragmentação para a qualidade de vida. É necessário considerar especificidades regionais como a extensão, a densidade, a localização.

\section{O caso da Região Norte}

A Região Norte (figura II) compreende sete Estados (Acre, Amazonas, Roraima, Amapá, Pará, Rondônia, Tocantins), possui uma área de 3’852,967.6 km² (IBGE, 2002) que corresponde a maior parte da área da Amazônia Brasileira e, embora apresente uma baixa densidade demográfica (de 3.35 habitantes por quilômetro quadrado enquanto a do Brasil era de $19.92 \mathrm{em} \mathrm{2000)} \mathrm{vem} \mathrm{se}$ destacando no contexto do país por vir se urbanizando de forma acelerada nas últimas décadas. Alguns números ilustram que o crescimento da população urbana e total foram superiores à média nacional.

Segundo IPEA/IBGE/Unicamp - Universidad de Campinas (2001), a taxa média anual de crescimento da população total entre 1970 e 1980 foi de 4.9\%, enquanto a média nacional foi de 2.5\%. Entre 1980-91 e 1991-96 essa situação se manteve e, novamente, a Região Norte teve taxas de crescimento da população total superiores à média nacional. Enquanto a Região Norte cresceu 3.9\%, em 1980-91, a taxa do Brasil foi de 1.7\%. Entre 1991-96, a região teve uma taxa de $2.4 \%$, sendo que o Brasil cresceu 1.4\%. Em relação à população urbana, as taxas de crescimento também foram superiores à média nacional. Nos mesmos períodos estas foram respectivamente de $6.6 \%$, 5.9\% e 3.5\%, enquanto à média nacional foi de 4.4\%, 3\% e 2.1\%.

Quanto ao grau de urbanização da Região Norte no período de 1950-2000, embora este não tenha sido superior à média na- 
Figura II

Localização dos municípios criados após 1988 na Região Norte, foco do estudo de caso deste trabalho - por Estado

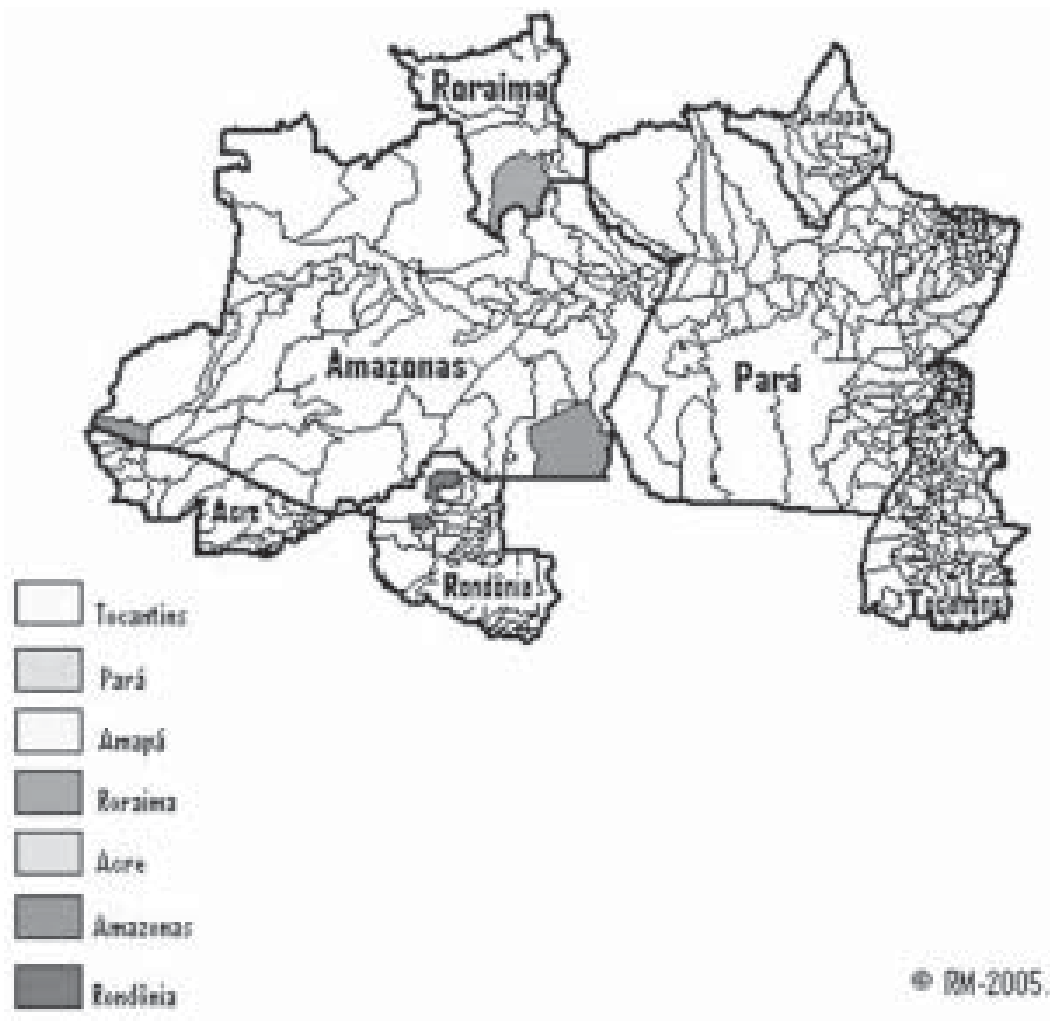

cional, sofreu um aumento gradativo ao longo deste período passando de 42.6\% (1970), 50.8\% (1980), 57.8\% (1991), alcançando 62.4\% (1996) (IPEA/IBGE/Unicamp, 2001).

Analisando-se a Região Norte sob o ponto de vista da fragmentação territorial é possível observar que nesta a fragmentação processou-se de maneira intensa. Considerando os sete estados, conforme o quadro 1 em anexo, o número de Municípios que existia antes da Constituição de 1988 e o ano de 2000, passou de 248 para 449. Destes, o Estado com mais Municípios em 2000, era o Pará, com 143, seguido pelo Tocantins, com 139, exatamente os mesmos que mais criaram novos Municípios: 81 em Tocantins e 56 no Pará.

Em contraponto, ainda de acordo com o quadro 1, o Estado que menos se fragmentou foi o Amazonas, onde apenas três no- 


\begin{tabular}{lccc}
\multicolumn{4}{c}{ Quadro 1 } \\
Número de municípios criados antes e depois de 198 \\
\hline & Antes & Depois & Total \\
\cline { 2 - 4 } & 12 & 10 & $\mathbf{2 2}$ \\
1. Acre & 5 & 11 & 16 \\
2. Amapá & 59 & 3 & 62 \\
3. Amazonas & 87 & 56 & $\mathbf{1 4 3}$ \\
4. Pará & 19 & 33 & 52 \\
5. Rondônia & 8 & 7 & 15 \\
6. Roraima & 58 & 81 & $\mathbf{1 3 9}$ \\
7. Tocantins & 248 & 201 & 449 \\
Total &
\end{tabular}

Fonte: Instituto Brasileiro de Geografia e Estatística (IBGE, 2003).

vos municípios foram criados. Os demais tiveram o número de municípios mais que duplicado após 1988.

Tendo em vista a impossibilidade de analisar a qualidade de vida em todos os 201 Municípios criados após 1988, inicialmente, dois critérios foram estabelecidos para selecionar alguns Municípios que se constituirão em estudos de caso do presente artigo: grau de urbanização superior a $50 \%$ e, simultaneamente, população total acima de 10 mil habitantes.

O patamar de 50\%, considerado médio, foi definido porque está se supondo que a criação de Municípios está relacionada com o crescimento urbano. Com esse critério, 124 dos 201 Municípios ficariam excluídos, restando 77. Entretanto, quando se observa o tamanho da população, verifica-se que 56 destes 77 têm menos de 10 mil habitantes. Com isso, apenas 21 Municípios seriam objeto de análise, implicando que os pertencentes aos Estados de Rondônia, Acre e Amapá estariam pouco representados e os do Amazonas e Roraima não apareceriam. Para tanto, baixou-se o patamar demográfico para 5 mil habitantes e abriu-se uma exceção para os Estados de Roraima e Amazonas, diminuindo-se o grau de urbanização para 40\%. Assim, chegouse a 36 Municípios envolvendo todos os Estados da Região Norte, sendo: 16 do Pará, 10 do Tocantins, 3 de Rondônia, 4 do Amapá, 2 do Amazonas, 1 de Roraima e 1 do Acre. Destes, 13 estão na faixa de 5 a 10 mil habitantes, 10 na faixa de 10 a 20 mil, 10 na faixa de 20 a 50 mil, 3 na faixa de 50 a 100 mil e, 1 com mais de 100 mil, significando que há uma certa proporcionalidade dessa distribuição com o número total de Municípios criados.

Uma vez definidos os critérios foi elaborada uma listagem contendo a relação dos 36 Municípios criados após 1988 (quadro 2 
Quadro 2

Municípios criados após 1988 na Região Norte - por Estado

\begin{tabular}{|c|c|c|c|c|c|c|c|}
\hline & $\mathrm{UF}^{1}$ & $\begin{array}{c}\text { Municípios } \\
\text { novos }\end{array}$ & Desmembrado $^{2}$ & $\begin{array}{c}\text { Ano } \\
\text { instalação }\end{array}$ & $\begin{array}{c}\text { População } \\
\text { total }^{3}\end{array}$ & $\begin{array}{c}\text { População } \\
\text { urbana }^{3}\end{array}$ & $\begin{array}{c}\text { Grau de } \\
\text { urbanização }\end{array}$ \\
\hline 1. & $\mathrm{AC}$ & Epitaciolândia & Brasiléia & $01 / 01 / 1993$ & 11,028 & 7,404 & 67.1 \\
\hline 2. & $\mathrm{AM}$ & Apuí & Novo Aripuanã & $01 / 01 / 1989$ & 13,864 & 6,126 & 44.2 \\
\hline 3. & $\mathrm{AM}$ & Guajará & Ipixuna & $01 / 01 / 1989$ & 13,220 & 6,220 & 47.0 \\
\hline 4. & $\mathrm{AP}$ & Laranjal do Jari & Mazagão & $01 / 01 / 1989$ & 28,515 & 26,792 & 93.9 \\
\hline 5. & $\mathrm{AP}$ & Porto Grande & Macapá & $01 / 01 / 1993$ & 11,042 & 7,374 & 66.8 \\
\hline 6. & $\mathrm{AP}$ & Santana & Macapá & $01 / 01 / 1989$ & 80,439 & 75,849 & 94.2 \\
\hline 7. & $\mathrm{AP}$ & Vitória do Jari & Laranjal do Jari & 01/01/1997 & 8,560 & 6,880 & 80.4 \\
\hline 8. & PA & Abel Figueiredo & $\begin{array}{l}\text { Bom Jesus do } \\
\text { Tocantins }\end{array}$ & 01/01/1993 & 5,957 & 4,897 & 82.2 \\
\hline 9. & PA & $\begin{array}{l}\text { Brejo Grande } \\
\text { do Araguaia }\end{array}$ & $\begin{array}{l}\text { São João do } \\
\text { Araguaia }\end{array}$ & 01/01/1989 & 7,464 & 4,255 & 57.0 \\
\hline 10. & PA & $\begin{array}{l}\text { Concórdia } \\
\text { do Pará }\end{array}$ & Bujaru & 29/01/1989 & 20,956 & 10,848 & 51.8 \\
\hline 11. & $\mathrm{PA}$ & Curionópolis & Marabá & 01/01/1989 & 19,486 & 13,250 & 68.0 \\
\hline 12. & PA & Dom Eliseu & Paragominas & 01/01/1989 & 39,529 & 23,801 & 60.2 \\
\hline 13. & PA & $\begin{array}{l}\text { Goianésia } \\
\text { do Pará }\end{array}$ & $\begin{array}{l}\text { Rondon do } \\
\text { Pará }\end{array}$ & 01/01/1993 & 22,685 & 14,878 & 65.6 \\
\hline 14. & $\mathrm{PA}$ & Mãe do Rio & Irituia & 01/01/1989 & 25,351 & 18,738 & 73.9 \\
\hline 15. & PA & Marituba & Benevides & 01/01/1997 & 74,429 & 64,884 & 87.2 \\
\hline 16. & PA & $\begin{array}{l}\text { Palestina } \\
\text { do Pará }\end{array}$ & $\begin{array}{l}\text { Brejo Grande } \\
\text { do Araguaia }\end{array}$ & 01/01/1993 & 7,544 & 3,840 & 50.9 \\
\hline 17. & PA & Parauapebas & Marabá & 01/01/1989 & 71,568 & 59,260 & 82.8 \\
\hline 18. & PA & $\begin{array}{l}\text { São Domingos } \\
\text { do Araguaia }\end{array}$ & $\begin{array}{l}\text { São João do } \\
\text { Araguaia }\end{array}$ & 01/01/1993 & 20,005 & 10,878 & 54.4 \\
\hline 19. & PA & $\begin{array}{l}\text { São João de } \\
\text { Pirabas }\end{array}$ & Primavera & 01/01/1989 & 17,484 & 9,832 & 56.2 \\
\hline 20. & PA & Tailândia & Acará & 01/01/1989 & 38,435 & 28,128 & 73.2 \\
\hline 21. & PA & Terra Santa & Faro & 01/01/1993 & 14,592 & 10,965 & 75.1 \\
\hline 22. & PA & Tucumã & $\begin{array}{l}\text { São Félix do } \\
\text { Xingu }\end{array}$ & 01/01/1989 & 25,309 & 16,496 & 65.2 \\
\hline 23. & PA & Ulianópolis & Paragominas & 01/01/1993 & 19,254 & 11,909 & 61.8 \\
\hline 24. & $\mathrm{RO}$ & Buritis & $\begin{array}{l}\text { Campo Novo } \\
\text { de Rondônia }\end{array}$ & 01/01/1997 & 25,668 & 15,334 & 59.7 \\
\hline 25. & $\mathrm{RO}$ & $\begin{array}{l}\text { Candeias } \\
\text { do Jamari }\end{array}$ & Porto Velho & 01/01/1993 & 13,107 & 9,354 & 71.4 \\
\hline 26. & $\mathrm{RO}$ & Itapuã do Oeste & Porto Velho & 01/01/1993 & 6,822 & 3,677 & 53.9 \\
\hline 27. & $\mathrm{RR}$ & Rorainópolis & $\begin{array}{l}\text { São João da } \\
\text { Baliza }\end{array}$ & 01/01/1997 & 17,393 & 7,185 & 41.3 \\
\hline 28. & TO & $\begin{array}{l}\text { Aliança do } \\
\text { Tocantins }\end{array}$ & Gurupi & 01/01/1989 & 6,177 & 5,120 & 82.9 \\
\hline 29. & TO & Barrolândia & $\begin{array}{l}\text { Miracema do } \\
\text { Tocantins }\end{array}$ & 01/06/1989 & 5,082 & 4,188 & 82.4 \\
\hline 30. & TO & $\begin{array}{l}\text { Buriti do } \\
\text { Tocantins }\end{array}$ & $\begin{array}{l}\text { São Sebastião } \\
\text { do Tocantins }\end{array}$ & 01/06/1989 & 7,842 & 6,116 & 78.0 \\
\hline 31. & TO & Colméia & Araguacema & 01/01/1997 & 9,352 & 6,358 & 68.0 \\
\hline 32. & TO & $\begin{array}{l}\text { Divinópolis } \\
\text { do Tocantins }\end{array}$ & $\begin{array}{l}\text { Miracema do } \\
\text { Tocantins }\end{array}$ & 01/06/1989 & 5,776 & 3,987 & 69.0 \\
\hline 33. & TO & $\begin{array}{l}\text { Lagoa da } \\
\text { Confusão }\end{array}$ & Cristalândia & 01/01/1993 & 6,168 & 3,396 & 55.0 \\
\hline 34. & TO & Palmas & Porto Nacional & 01/01/1990 & 137,355 & 134,179 & 97.7 \\
\hline 35. & $\mathrm{TO}$ & Praia Norte & Itaguantins & 01/06/1989 & 6,781 & 3,475 & 51.2 \\
\hline 36. & TO & $\begin{array}{l}\text { Santa Fé } \\
\text { do Araguaia }\end{array}$ & Araguaína & 01/01/1993 & 5,507 & 3,368 & 61.1 \\
\hline
\end{tabular}

${ }^{1}$ AC: Acre, AM: Amazonas, AP: Amapá, PA: Pará, RO: Rondônia, RR: Roraima, TO: Tocantins.

${ }^{2}$ Fonte: Instituto Brasileiro de Geografia e Estatística (IBGE, http://www.ibge.gov.br), Informações especiais solicitadas em junho de 2003.

${ }^{3}$ Fonte: Instituto Brasileiro de Geografia e Estatística (IBGE, http://www.ibge.gov.br), Censo Demográfico 2000 . 
e figura II em anexo) juntamente com os Municípios equivalentes dos quais estes novos foram desmembrados.

Para avaliar até que ponto a fragmentação municipal ocorrida na Região Norte após 1988 contribuiu para melhorar ou não a qualidade de vida nos Municípios novos e nos que deram origem a estes, escolheu-se como indicador, a título de ensaio, o número de domicílios ligados à rede geral de água. Esta escolha justifica-se porque os Indicadores de Desenvolvimento Sustentável IBGE (2002), consideram que a água tratada é fundamental para a melhoria das condições de saúde e higiene da população e, associado a informações ambientais e socioeconômicas, incluindo outros serviços de saneamento, saúde, educação e renda, é um indicador universal de desenvolvimento sustentável. "Trata-se de um indicador importante para a caracterização básica da qualidade de vida da população, quanto ao acompanhamento das políticas públicas de saneamento básico e ambiental” (IBGE, 2002: 114).

A partir das informações levantadas sobre população total, total de domicílios e total de domicílios ligados a rede geral de abastecimento de água para os Municípios antigos e os novos, criados após 1988, foram realizadas duas comparações: a primeira entre os dados dos Municípios antigos em 1980 e 2000; e a segunda, entre os Municípios antigos em 1980 e eles mesmos em 2000 juntamente com os dados dos novos Municípios que deles foram desmembrados.

A primeira comparação mostrou que, na maior parte dos Municípios antigos houve uma melhoria na porcentagem de domicílios ligados à rede geral de abastecimento de água, sendo que em alguns de Tocantins, como Miracema do Tocantins, Araguaína, Cristalândia e Porto Nacional, essa melhoria, entre 1980 e 2000, foi muito significativa. No primeiro passou de $9.1 \% \mathrm{em}$ 1980 para $80.2 \%$ em 2000 , no segundo de $19.6 \%$ para $84.4 \%$, no terceiro de $24.4 \%$ para $81.7 \%$ e, no último, de $24.2 \%$ para 79.4\%. Apenas nos Municípios de Macapá (AP) e São Félix do Xingu (PA) houve um declínio na porcentagem de domicílios ligados à rede geral, caindo, respectivamente, de $57.8 \%$ em 1980, para $53.2 \%$ e de $15 \%$ para $5 \%$ em 2000 . Entretanto, cabe ressaltar que, em alguns Municípios como Mazagão que já tinha em 1980 uma pequena porcentagem de domicílios ligados à rede geral (0.9\%), embora esse número tenha aumentado para $13.8 \% \mathrm{em}$ 2000, essa melhoria foi pequena.

Quanto à segunda comparação, pode-se constatar que na maior parte dos Municípios as porcentagens de domicílios ligados à rede 
geral de abastecimento de água apresentaram uma melhoria expressiva em seus números. Destaque-se Porto Nacional (TO), onde a população que vivia em seu território em 1980 possuía $24.2 \%$ de seus domicílios ligados a rede geral de abastecimento de água, número este que analisado conjuntamente com Porto Nacional e Palmas, em 2000, passa a ser de 89.6\%. Já Miracema do Tocantins (то), cujo percentual era de $9.1 \%$ em 1980 , passou para $75.1 \%$ em 2000, considerando-se não só Miracema de Tocantins, como os novos Municípios criados a partir do seu território: Barrolândia e Divinópolis de Tocantins. E por fim, Araguaína, com 19.6\% em 1980, atingiu 83.2\% em 2000 (considerando-se Araguaína e o Município que dele foi desmembrado, Santa Fé do Araguaia).

Um outro tipo de análise, realizada também com o número de domicílios ligados à rede de água, mas usando o atendimento per capita, mostra que, dentre os Municípios antigos, em 1980, destacam-se como melhores: Macapá onde, para cada 1000 pessoas, 160 moravam em domicílios ligados a rede geral e Porto Velho 71. Ao contrário, os piores eram Acará (PA) com sete e Ipixuna (AM) com quatro.

Com relação aos 36 novos Municípios, os dados mostram que 20 deles, em 2000, possuíam mais de 100 pessoas em cada 1000 residindo em domicílios ligados à rede geral de abastecimento de água, demonstrando que estes são mais bem atendidos do que os Municípios antigos. O principal destaque é para o Município de Palmas (TO) onde, em cada 1000 pessoas 236 residiam em domicílios que tinham acesso à rede de abastecimento de água. Entre os com pior situação, estavam Buriti (RO) e Apuí (AM) que apresentavam números menores que um.

Em síntese, a análise do número de domicílios ligados à rede geral de água, em 33 Municípios antigos e 36 novos, indica que houve uma melhoria na maior parte deles comparando-se os anos de 1980 e 2000 . No entanto, a análise deixou claro também que, apesar de alguns números terem aumentado, a parcela da população que reside em domicílios ligados à rede geral de abastecimento de água ainda é muito pequena, como confirma a Pesquisa Nacional de Saneamento Básico - PNSB realizada pelo IBGE (2005) nos 5,507 Municípios do Brasil.

No que se refere ao abastecimento de água, os dados desta pesquisa mostram que, comparando-se às demais, a Região Norte (juntamente com a Nordeste) é a que apresenta os piores números relacionados a este indicador. Em relação à quantidade de domicílios abastecidos por rede geral, enquanto a Região Sudes- 
te se destaca por apresentar em 2000 uma porcentagem de 70.5\% de domicílios atendidos, na Região Norte a proporção é de apenas $44.3 \%$. A Região Norte é também a que apresenta o mais baixo índice de ligações com medidores (hidrômetros). Enquanto no Sudeste $91 \%$ das ligações são medidas, na Região Norte esse número é de apenas $37 \%$. A pesquisa ilustra também que no que se refere ao volume da água tratada, há uma diferença de padrão na Região Norte com as outras regiões do país. Enquanto no Nordeste, Sudeste, Sul e Centro-Oeste mais de 90\% da água distribuída recebem algum tipo de tratamento, no Norte este percentual é somente de 67.6\%. Além disto, dos 116 Municípios sem serviço de abastecimento de água por rede geral no Brasil, a maior parte deles está situada na Região Norte e Nordeste, o que força estas localidades a terem que utilizar como alternativas para o abastecimento: chafarizes e fontes, poços particulares e caminhões-pipa.

Por fim, outro fator agravante apresentado pela mesma pesquisa é que a abrangência do abastecimento de água varia de acordo com a quantidade de população dos Municípios. Nesse sentido, "os menores municípios apresentam maior deficiência nos serviços, e apenas $46 \%$ dos domicílios situados em municípios com até 20000 habitantes contam com abastecimento de água por rede geral” (IBGE, 2002: 32). Tendo em vista que boa parte dos novos municípios da Região Norte se encontra nessa faixa de população, como já discutido anteriormente, a situação da região é bastante preocupante, requerendo uma maior atenção por parte dos governantes.

\section{Conclusões}

Este trabalho teve como objetivo avaliar as mudanças ocorridas na qualidade de vida da população dos novos Municípios da Região Norte usando-se como indicador, o número de domicílios ligados a rede geral de água. As informações obtidas a partir da comparação entre os dados do Censo Demográfico de 1980 e 2000 do IBGE comprovaram, em quase todos os casos, que houve de fato uma melhoria. Mas serviram também para ilustrar que na maioria deles estas condições de vida ainda estão muito abaixo daquelas encontradas nas demais regiões do país. Para comprovar efetivamente estas conclusões faz-se necessário agregar outros indicadores (de saúde, educação, renda) a fim de que se possa ter uma visão mais abrangente da situação dos novos Municípios 
criados na Região Norte a partir de 1988. Acredita-se que o conhecimento dessa realidade regional possa subsidiar decisões governamentais de investimento que, em última análise, buscam promover o desenvolvimento e a melhoria da qualidade de vida da população. Vale ainda registrar que esta região envolve a maior parte da Amazônia Brasileira, uma das áreas mais visadas em termos internacionais na última década.

\section{Bibliografia}

Becker, Bertha K. (1990), Amazônia, Ática, São Paulo.

(2000), "Cenários de curto prazo para o desenvolvimento da Amazônia”, Cadernos do IPPUR, Universidade Federal do Rio de Janeiro, jan/jul, xIV (1): 53-86.

(2003), "Amazônia: mudanças estruturais e urbanização", in Maria Flora Gonçalves et al. (orgs), Regiões e cidades, cidades nas regiões: o desafio urbano-regional, UNESP/ANPUR, São Paulo.

Borja, Jordi (1997), "As cidades e o planejamento estratégico: uma reflexão européia e latino-americana”, in Tânia Fischer (org.), Gestão contemporânea. Cidades estratégicas e organizações locais, Fundação Getúlio Vargas, Rio de Janeiro, pp. 76-99.

Corrêa, Roberto Lobato (1994), “Territorialidade e corporação: um exemplo", in Milton Santos et al. (orgs.), Território, globalização e fragmentação, Hucitec/AnPUR, São Paulo.

(1995), "Espaço: um conceito-chave da Geografia", in Iná Elias de Castro, Paulo César da Costa Gomes e Roberto Lobato Corrêa, Geografia: conceitos e temas, Bertrand Brasil, Rio de Janeiro.

Fernandes, Maria Augusta (1997), Indicadores de qualidade de vida: um estudo de caso em quatro áreas periféricas do Distrito Federal, dissertação (Mestrado em Planejamento Urbano), Faculdade de Arquitetura e Urbanismo, Universidade de Brasília. 
Ferreira, Olavo Leonel (1986), História do Brasil, Ática, São Paulo.

Freitas, Ronald (1998), “Tem festa no interior. Leis brandas e controles frágeis levaram à explosão do número de municípios no país desde 1988: muitos deles sem estrutura alguma”, Época, 15 de fevereiro/junho, 1 (4): 30-33.

IBAM (Instituto Brasileiro de Administração Municipal) (2004), O Municipio no Brasil, http://www.ibam.org.br.

IBGE (2002), Indicadores de desenvolvimento sustentável, IBGE, Diretoria de Geociências, Rio de Janeiro.

(2003), informações especiais, Denise Teixeira Medeiros, DEATI/CDDI/IBGE.CDDI.DI@ibge.gov.br, solicitação de informações, proto de 14506 (mensagem pessoal), mensagem recebida de IBGE Antendimento Cidades@webmaster @ibge.gov.br em 3 junho.

(2005), Censo Demográfico, http://www.ibge.gov.br.

IPEA/IBGE/Unicamp (2001), Caracterização e tendências da rede urbana do Brasil: redes urbanas regionais: Norte, Nordeste e Centro-Oeste, IPEA, Brasília.

Lefebvre, Henri (1999), A cidade do capital, DP \& A, Rio de Janeiro.

Limana, Amir (1999), “O processo de descentralização políticoadministrativa no Brasil”, Scripta Nova. Revista Electrónica de Geografía y Ciencias Sociales, Universidad de Barcelona, ago, 45 (21), http://www.ub.es/geocrit/sn-45-21.htm.

Nicácio, Ricardo Manoel (1982), O impacto da Zona Franca sobre a qualidade de vida em Manaus, ESAF, Brasília.

Preteceille, Edmond (1996), "Segregação, classes e política na grande cidade", Cadernos do IPPUR/UFRJ, Rio de Janeiro, ago/ dez, $x(2): 15-37$.

Raffestin, Claude (1993), Por uma geografia do poder, Ática, São Paulo. 
Rodrigues, Alcides Redondo (2003), A evolução do Município no Brasil, IвAм, http://www.ibam.gov.br.

Rolnik, Raquel (1988), O que é cidade? Editora Brasiliense, São Paulo.

Souza, Maria Adélia Aparecida de (1997), Cidade: Lugar e geografia da existência, $5^{\circ}$ Simpósio Nacional de Geografia Urbana, de 21 a 24 de outubro, Salvador.

Souza, Celina (1998), Relações intergovernamentais e a reforma da administração pública local, trabalho apresentado no Seminário A Reforma da Administração Pública: Possibilidades e Obstáculos, Recife, 20-21 ago. Disponível em http://www.fundaj.gov.br/docs/eg/semi10.rtf.

Souza, Marcelo José (1995), “O território: sobre espaço e poder, autonomia e desenvolvimento", in Iná Elias Castro et al. (orgs.). Geografia: conceitos e temas, Bertrand, Rio de Janeiro, pp. 77-116.

Steinberger, Marília (1994), Uma história dentro da História: personagens no tempo e no espaço, tese de doutoramento defendida junto à FAu/usP (mimeo), janeiro, São Paulo.

(2001a), "A rede urbana no zoneamento ecológico-econômico", Memórias das Discussões sobre Zoneamento Ecológico-Econômico, SDS/MMA, Brasília, CD-ROM.

(2001b), "A (re)construção de mitos sobre a (in)sustentabilidade do(no) espaço urbano", Revista Brasileira de Estudos Urbanos e Regionais, maio, 4: 9-32.

e Marta Romero (2000), "Reflexões preliminares sobre as dimensões demográficas urbanas do zoneamento ecológico-económico", Anais XII Encontro ABEP, Caxambu, CDROM.

e Ignez B. Ferreira (2003), "Reflexões sobre uma política nacional de desenvolvimento urbano para o Brasil”, $I X$ 
Colóquio Internacional sobre Poder Local, Nepol/UfBA, Salvador, CD-ROM.

Veiga, José Eli da. (2002), Cidades imaginárias: o Brasil é mais urbano do que se calcula, Autores Associados, Campinas.

Villarinho, Adriana de Lima (2000), Urbanização acelerada e qualidade de vida, 156 f., dissertação (Mestrado em Geografia), Instituto de Ciências Huamanas/Departamento de Geografia, Universidade de Brasília.

Weber, Max (1987), "Conceito e categoria de cidades", in Otávio Velho (org.). O fenômeno urbano, Zahar Editores, Rio de Janeiro.

Recibido: 1 de julio de 2005. Reenviado: 18 de septiembre de 2005. Aceptado: 4 de octubre de 2005.

Marília Steinberger, economista, doctora en planeación urbana, regional y ambiental por la Universidad de São Paulo. Profesora de Geografía Política y Geografía Económica en los cursos de graduación y maestría del Departamento de Geografía de la Universidad de Brasilia (UnB). Desarrolla investigaciones en el Núcleo de Estudios Urbanos y Regionales (NEUR/UnB) en las áreas de política urbana, regional y ambiental con trabajos publicados sobre estos temas. Entre sus publicaciones cabe destacar la organización del libro Espaço, território e ambiente em políticas públicas, Paralelo 15, 2005, Brasilia (en imprenta); junto con Diana Meirelles da Motta y Adauto Lúcio Cardoso, Instrumentos de planejamento e gestão urbana: Brasília e Rio de Janeiro, IPEA, Brasilia, 2003; y con Theodelina Amado tiene el artículo "Zonificación ecológico-económica como instrumento de gestión ambiental urbana-rural: el caso de la Amazônia brasileña", Cuadernos de Cendes, Caracas, vol. 53, pp. 71-84, 2003.

Regina de Souza Maniçoba es geógrafa, maestra en geografía por la Universidad de Brasilia y está por doctorarse en el Centro de Desarrollo Sustentable en la misma universidad. Ha desarrollado investigaciones referentes a la urbanización, sobre la cual ya 
posee los siguientes trabajos: en coautoría con Marília Steinberger, "Brasília capital nacional-regional: Brasília cidade mundial?”, Publicaciones del $v$ Seminario Internacional de la Red Iberoamericana de Investigadores sobre Globalización y Territorio, Toluca, México, 1999 (CD-ROM); "Descentralização e fragmentação territorial no período pós constituição brasileira de 1988: o caso da região norte", Publicaciones del VIII Seminario Internacional de la Red Iberoamericana de Investigadores sobre Globalización y Territorio, Río de Janeiro, 2004 (CD-ROM), y "Brasília como cidade mundial sob o ponto de vista de aspectos não-econômicos", revista Espaço e Geografia, Brasília, Departamento de Geografía y Programa de Posgrado en Geografía, año 4, núm. 1, pp. 119-132, 2001. 